\title{
The Effectiveness of a Professional Development Program on the use of STEM-based 5E Inquiry Learning Model for Science Teachers in China
}

\author{
Eng Tek Ong ${ }^{1 *}$, Xingkai Luo², Jing Yuan², Janchai Yingprayoon ${ }^{3}$ \\ ${ }^{1}$ Department of Educational Studies, Faculty of Human Development, Sultan Idris Education University, Tanjung Malim, Perak, Malaysia, \\ ${ }^{2}$ Research Institute of Science Education, Guangxi Normal University, Guilin, China, ${ }^{3}$ International College, Suan Sunandha Rajabhat University, \\ Srijutapa Building, Dusit, Bangkok, Thailand
}

*Corresponding Author: ong.engtek@fpm.upsi.edu.my

\section{ABSTRACT}

This study aimed to determine the effectiveness of a professional development program on the use of a STEM-based 5E Inquiry Learning Model in enhancing the learning of STEM-based Inquiry Learning Model among 78 in- and pre-service science teachers. The topic electric circuit was used as the context of the study. Given the aim and the exploratory nature of this study, a triangulation mixed-methods design was employed: One-group pretest-posttest design which involved a single group that was pre-tested, exposed to the STEM-based 5E Inquiry Learning Model, and post-tested. This was triangulated by the qualitative responses from the participants' reflections. The analysis of the quantitative dataset using the paired samples t-test indicated that the post-test mean score was statistically significantly higher than the pre-test mean score and that the effect size obtained was educationally significant. Further analyses by gender and participants' teacher status, indicated a non-significant difference, giving credence that this result was truly the outcome of the intervention (treatment) effect instead of any disguised effect. The analysis of qualitative data through a recursive process resulted in the crystallization of three overarching key themes: Enhanced knowledge on the content used, empowered pedagogical skills on STEM-based Inquiry Learning, and heightened classroom management skill on promoting collaboration in the classroom.

KEY WORDS: STEM; 5E inquiry learning model; professional development; teacher education; science teachers

\section{INTRODUCTION}

I n 2001, following China's launching of its curriculum reform of basic education (Ministry of Education, 2001), a series of curriculum standards and policy documents were conceptualized which included the integrated science curriculum standards for primary and middle schools, individual subject (physics, chemistry, biology, and geography) curriculum standards for middle and high schools (Wang et al., 2016). In essence, the curriculum reform specifies six areas of the largescale curriculum change: (1) Mode of learning (from passive knowledge adsorption to that of active knowledge construction); (2) curriculum structure (from a disciplined-based to that of integrated and adaptive approaches to knowledge); (3) curriculum content (from textbook-based knowledge to that of knowledge acquired based on students' experience and interests and is connected to the broader scientific, technological, and social developments); (4) pedagogical (from lecture and rote learning to that of inquiry and problem-based learning, cooperative learning that promotes communication, and critical thinking and creative problem-solving skills); (5) evaluation (from selection and placement focus to that of one that improves learning and instruction); and (6) curriculum administration (from top-down, centralized control to that of multi-level management adaptive to regional, provincial, local school, and student needs).
Fast forward about one and a half decades, China has seen the emphasizing of the importance of science education as China's Ministry of Education issued new guidelines for science education in February 2017, requiring elementary schools to make science a compulsory subject for first-grade students (Xinhua, 2017). In addition, the Ministry of Education has also officially included STEM Education into the primary school curriculum, giving the government's inaugural official recognition of STEM Education. Hence, the China Elementary School Science Curriculum Standard for Compulsory Education with an explicit integration of STEM was published. This elementary science curriculum encompasses four major course contents, namely, Material Science, Life Science, Earth and Universe Science, and Technology and Engineering (Ministry of Education, 2017). Later, in May 2018, the 2029 Action Plan for China's STEM Education was revealed and launched in Beijing. This action plan aims to benefit as many Chinese students as possible from STEM Education, imbuing them with scientific thinking and inculcating them with the ability to innovate in terms of science and technology.

The educational reform that China is undergoing, particularly in terms of science education, entails a shift from a rigid, fixed curriculum and one-way teacher-centered didactic pedagogy to a more flexible, school-based curriculum and student-centered 
inquiry-based pedagogy. However, the research conducted by Dai et al. (2001) indicates that while the Chinese teachers are generally receptive to inquiry-based pedagogy, they are, in reality, facing "practical constraints in fully implementing it" (p. 139). Similarly, Chinese teachers are also having problems in enacting and implementing a STEM-based lesson in their respective classes in the face of reform, whereby STEM Education has been given credence. Zhang (2018) reported that STEM Education in China was facing a shortage of both professional science teachers and inadequate training for existing teachers. It is worrying when Zhang (2018) presented an alarming statistics in that $80.5 \%$ of teachers involved in STEM subjects while fulfilling the formal requirements to be a science teacher in China, they received inadequate training, particularly on how science could be taught in an integrated manner for the teaching of STEM. Accordingly, Zeng et al. (2019) strongly recommended that crucial attention is needed for the professional development of science teachers in China.

Given the discussion from the preceding paragraphs, the Research Institute of Science Education, Guangxi Normal University has been tasked and given sufficient funding by the Guangxi Department of Education and the Ministry of Education, China, to conduct a series of professional development programs for groups of pre- and in-service Chinese science teachers aimed at capacity building in terms of the ability to implement STEM-based 5E Inquiry Learning Model. Therefore, the following research questions emerged with regard to the effect of the professional development program on STEM-based 5E Inquiry Learning Model:

1. What is the effect of the STEM-based 5E Inquiry Learning Model professional development program on the learning achievement of the participants in the topic on the electric circuit?

2. What are the views by means of self-perceived written reflections on what the participants have gained which they did not know before the professional development on STEM-based 5E Inquiry Learning Model?

\section{STEM-based 5E Inquiry Learning Model: A Review}

A review of the literature indicates that there are many inquirybased teaching methodologies such as General Inquiry Model (Eggen and Kauchak, 2012) and Suchman Inquiry Model (Suchman, 1966). However, this section gives a snapshot of the STEM-based 5E Inquiry Learning Model (Bybee and Landes, 1990).

Essentially, the STEM-based 5E Inquiry Learning Model comprises the following phases: Engagement, exploration, explanation, elaboration, and evaluation. Underlying each of the phases is a specific pedagogical function that contributes to the teacher's coherent instruction and to the learners' construction of knowledge. It is STEM-based in view of the fact that the STEM elements are incorporated into the 5E Inquiry Learning Model. For example, the engineering component is integrated into the elaboration phase, where students are encouraged to design and construct on the basis of the science and mathematics knowledge that they have just acquired using the technological tools. Table 1 summarizes the pedagogical function in each of the five phases of the $5 \mathrm{E}$ Inquiry Learning Model by Bybee et al. (2006). The Bybee et al. (2006) model is a well-conceptualized model where the pedagogical function for each of the phases is clearly articulated. Therefore, the professional development program in this study which is concisely described in the methodological section is grounded in this model.

\section{METHODOLOGY}

This study employed a triangulation mixed-methods design, which entailed the collection of both quantitative and qualitative data concurrently or simultaneous during the study and comparison of the results from both quantitative and qualitative analyses to determine if the two databases yielded similar results (Creswell, 2008). Such a triangulation

\begin{tabular}{|c|c|}
\hline Phase & Summary of pedagogical function \\
\hline Engagement & $\begin{array}{l}\text { The teacher or a curriculum task accesses the learners' } \\
\text { prior knowledge and helps them become engaged in } \\
\text { a new concept through the use of short activities that } \\
\text { promote curiosity and elicit prior knowledge. The } \\
\text { activity should make connections between past and } \\
\text { present learning experiences, expose prior conceptions, } \\
\text { and organize students' thinking toward the learning } \\
\text { outcomes of current activities }\end{array}$ \\
\hline Exploration & $\begin{array}{l}\text { Exploration experiences provide students with a common } \\
\text { base of activities within which current concepts (i.e., } \\
\text { misconceptions), processes, and skills are identified and } \\
\text { conceptual change is facilitated. Learners may complete } \\
\text { lab activities that help them use prior knowledge to } \\
\text { generate new ideas, explore questions and possibilities, } \\
\text { and design and conduct a preliminary investigation }\end{array}$ \\
\hline Explanation & $\begin{array}{l}\text { The explanation phase focuses students' attention on a } \\
\text { particular aspect of their engagement and exploration } \\
\text { experiences and provides opportunities to demonstrate } \\
\text { their conceptual understanding, process skills, or } \\
\text { behaviors. This phase also provides opportunities for } \\
\text { teachers to directly introduce a concept, process, or skill. } \\
\text { Learners explain their understanding of the concept. } \\
\text { An explanation from the teacher or the curriculum may } \\
\text { guide them toward a deeper understanding, which is a } \\
\text { critical part of this phase }\end{array}$ \\
\hline Elaboration & $\begin{array}{l}\text { The teacher challenges and extends students' conceptual } \\
\text { understanding and skills. Through new experiences, the } \\
\text { students develop a deeper and broader understanding, } \\
\text { more information, and adequate skills. Students apply } \\
\text { their understanding of the concept by conducting } \\
\text { additional activities. The components of technology } \\
\text { and engineering in STEM are exemplified and given } \\
\text { prominence in this phase by providing students the } \\
\text { opportunity to design and construct }\end{array}$ \\
\hline Evaluation & $\begin{array}{l}\text { The evaluation phase encourages students to assess their } \\
\text { understanding and abilities and provides opportunities } \\
\text { for teachers to evaluate student progress towards } \\
\text { achieving the educational objectives }\end{array}$ \\
\hline
\end{tabular}

Source: Bybee et al. (2006. p. 2) 
of quantitative and qualitative data purports to provide a fuller and deeper understanding of the phenomenon at hand (Bogdan and Biklen, 2003; Denzin and Lincoln, 2000) - in this case, the impact of STEM-based 5E Inquiry Learning Model professional development program. Given the exploratory nature of this research, the "one-group pretest-posttest design" (Gay and Airasian, 2000. p. 389) was deemed appropriate.

This design involved a single group that was pre-tested, exposed to treatment, and post-tested. While it is acknowledged that history and maturation were not controlled, the relatively short period of time (e.g., 6-h intervention program) would likely to ameliorate these threats to internal validity. In addition, qualitative responses in terms of participants' reflections were gathered so as to illuminate what they have gained the professional development program which they did not know earlier.

The participants of this research project comprised a total of 78 pre- and in-service science teachers from various provinces in China. While the pre-service teachers hailed mainly from the Guangxi Normal University and had been selected by virtue of being the helpers in the training program, the in-service teachers, meanwhile, were nominated by the education departments from various provinces to attend the professional development program. The teacher selection criteria used by the various education departments are: (1) The teachers had not attended any national or provincial in-service training and (2) the teachers have the potential to cascade the knowledge acquired to other teachers within their educational communities. Overall, the composition of the pre- and inservice teachers is given in Table 2 .

The pre-test and post-test inventories were basically the same 9-item inventory that aimed to gauge the participants' understanding of the electric circuit. This inventory has sufficient validity in that every single item subsumes within the content coverage of an electric circuit, which was used as the context for the intervention. Furthermore, the electric circuit was employed as the context in training on the use of the STEM-based 5E Inquiry Learning Model because many science teachers do have misconceptions about the concept of an electric circuit (Gunstone et al., 2009; Moodeley and Gaigher, 2017). Equally, it is hoped that, upon successful restructuring of their misconceptions on the concept of an electric circuit, the participating teachers would also be able to not only have a good grasp of the 5E Inquiry Learning model but also to employ it in their quest to help their students make sense of electric circuit which is one of the problematic topics in the learning of science (Soeharto et al., 2019).

\begin{tabular}{lcc}
\hline \multicolumn{3}{l}{ Table 2: Overall composition of pre-and in-service teachers } \\
\hline Participants & Frequency & Percent \\
\hline Pre-service & 10 & 12.8 \\
In-service & 68 & 87.2 \\
Total & 78 & 100.0 \\
\hline
\end{tabular}

The 6-h professional development program on the STEM-based 5E Inquiry Learning Model was conducted on July 27, 2019. This program was conducted at the Research Institute of Science Education, Guangxi Normal University using the STEMbased 5E Inquiry Learning Model (Bybee et al., 2006) which essentially comprises the following five phases, namely, (1) engagement; (2) exploration; (3) explanation; (4) elaboration; and (5) evaluation, using the context of an electric circuit. The specific activities (e.g., what actually transpired within the 6-h intervention) were a general discussion of what, why, and how of STEM Education and this was followed by the "modeling of model" session in which participants acted as students while the first (and corresponding) author as the teacher.

In the engagement phase, students were given a worksheet depicting nine pictures of an electric circuit and they needed to make a prediction as to whether the light bulb will light or otherwise for each circuit. In the exploration phase, students were placed in groups of four, given the necessary materials, and asked to test if their predictions were correct. In the explanation phase, students were asked to make sense of the electric circuit on the basis of the experiments or exploration that they had conducted before individual students were called upon to share with the class. The teacher added on what was not discussed by the students. In the elaboration phase, students were given additional materials and were asked to make a construction of torchlight using the knowledge gained. Finally, in the evaluation phase, students were once again given the prediction sheet that was used in the engagement phase.

\section{FINDINGS}

\section{Quantitative Analysis}

The quantitative result as shown in Table 3 indicates that the t-test for paired samples yielded at 11.94 which was statistically significant $(\mathrm{p}<0.001)$ and a "large" (Cohen, 1988) effect size of +1.68 that was educationally significant. The mean score obtained in the post-test (96.72) was statistically significantly higher than the mean score obtained for the pre-test (72.22). Therefore, the post-test mean score for the group of 78 participants shows an appreciably higher degree of knowledge on electric circuits than did their pre-test mean score.

It is understandable for critics to be skeptical of the results presented on the basis of the possible initial (pre-intervention) and post-intervention differences between gender which may give rise to the gender effect rather than the treatment effect. As such, one further analysis was performed to dispel the suspicion and to draw a firmer conclusion. The analysis aimed to determine if there were any significant differences in pre-test and post-test mean scores between the male and

\begin{tabular}{|c|c|c|c|c|c|c|c|c|}
\hline \multicolumn{3}{|c|}{ Pre-test } & \multicolumn{3}{|c|}{ Post-test } & \multirow[t]{2}{*}{$t$} & \multirow[t]{2}{*}{$\rho$} & \multirow[t]{2}{*}{$\Delta^{+}$} \\
\hline$n$ & Mean & SD & $n$ & Mean & SD & & & \\
\hline 78 & 72.22 & 19.35 & 78 & 96.72 & 7.18 & 11.94 & $<0.001$ & +1.68 \\
\hline
\end{tabular}


the female participants. The results indicate that there were no significant differences between the pre-test mean scores $($ male $=75.16$, female $=69.95 ; t=1.183, \rho=0.240>0.05)$ and the post-test mean scores $($ male $=96.41$, female $=96.97$; $\mathrm{t}=0.342, \rho=0.31>0.05$ ).

Furthermore, as shown in Table 4, an independent samples t-test was conducted for the pre-test data and again, for the posttest data to compare the pre-intervention and post-intervention differences between the pre-service and in-service teachers. These analyses aimed to determine if there were any significant differences in pre-test and post-test mean scores between the pre- and in-service teachers. As shown in Table 4, the results indicate that there were no significant differences between the pre- and in-service teachers in their pre-test $(\mathrm{t}=0.58, \rho=0.563$ $>0.05)$ and post-test $(t=0.55,0=0.585>0.05)$.

Therefore, the analysis by gender and by participants' teacher status (i.e., pre-service versus in-service) further confirmed the earlier finding that the 78 participants have acquired a markedly higher level of knowledge in an electric circuit as the results of the professional development program on STEM-based 5E Inquiry Learning Model, and this is neither due to any disguised gender effect nor teacher status effect.

\section{Qualitative Analysis}

Given the Research Question 2 sought the views of the participants by means of self-perceived written reflections on what they have gained which they did not know before the professional development on STEM-based 5E Inquiry Learning Model, thematic analysis was used as the main analysis procedure to analyze the self-reflection data acquired (Braun and Clarke, 2006). Underneath each theme that emerges would be examples from the written self-reflections of participants that resoundingly supported the conceptualized theme. The analyses of the participants' self-perceived written reflections on what they now knew which they did not know before the professional development on STEM-based 5E Inquiry Learning Model indicated the emergence of the following three themes:

\section{Enhanced Knowledge on the Content Used}

While the participants have learned about the electric circuit in their earlier science education at school and college levels, many were not aware of the two terminals of a light bulb, located at the metal tip of base and metal around the base, as shown in Figure 1. Instead, they thought that one is a positive terminal while the other, the negative terminal.

After the exploration and explanation phases, participants gained an enhanced knowledge and understanding of the two

\begin{tabular}{|c|c|c|c|c|c|c|c|c|}
\hline \multirow[t]{2}{*}{ Test } & \multicolumn{3}{|c|}{ Pre-service teachers } & \multicolumn{3}{|c|}{ In-service teachers } & \multirow[t]{2}{*}{$t$} & \multirow[t]{2}{*}{$\rho$} \\
\hline & $\mathrm{n}$ & Mean & SD & $\mathrm{n}$ & Mean & SD & & \\
\hline Pre-test & 10 & 75.56 & 16.40 & 10 & 71.73 & 9.37 & 0.58 & 0.563 \\
\hline Post-test & 68 & 95.56 & 9.37 & 68 & 96.90 & 6.88 & 0.55 & 0.585 \\
\hline
\end{tabular}

terminals of a bulb, as indicated in the following reflections:

Before this class, I did not know the metal part of the small light bulb, and the part that protruded underneath could be seen as two terminals or contact points. After doing the experiment, I got a deeper understanding of the internal structure of the small light bulb, and I know that the two terminals on the bulb are neither a positive nor a negative terminal.

(Participant \#1)

The battery has positive and negative terminals. Hence, I always thought that no matter how the battery and bulb are connected by the wire, it must follow that the positive terminal of the battery must be connected to the negative terminal of the bulb. But now, I knew that any of the two terminals of the bulb could be connected to either the positive or negative terminal of the battery.

\section{(Participant \#12)}

Initially, I simply relied on the positive and negative poles of the battery to determine if the light bulb would light, and so my guesses as to which bulbs would light and which bulb would not light were all in a mess. When I did the exploration with the battery and the bulb, I discovered the two terminals of the bulb.

(Participant \#16)

Some participants had the pre-instructional view that the "black" base was one of the points which conduct electricity. However, after the exploration phase, they now knew that the "black" base was indeed an insulating material as indicated by the following direct quotes:

Before class, I thought that the black light bulb was a conductor. However, after the exploration, I realized that it was in fact an insulator that insulates the conductor terminal of the bulb.

(Participant \#6)

I did not know the black part under the light bulb was an insulator, but now I knew.

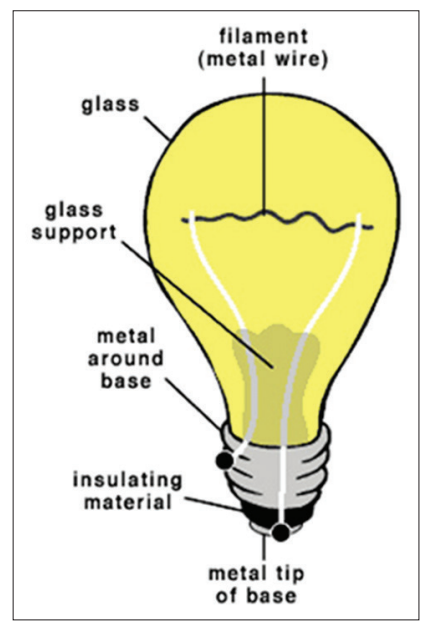

Figure 1: Structure of an electric bulb. Source: https://educationwithfun. com/course/view.php?id $=55 \&$ section $=7$ 
(Participant \#8).

When the prediction sheet was given to me, I did not quite understand the structure of the light bulb. I did not consider that the ring (i.e., the metal around the base) and the metal tip at the base were conductors, so I think that the bulbs in the nine pictures from A to I will not light up. But then, during exploration with my classmates, the discussion that we had made me aware that the iron ring and the tip at the base are actually terminals that conduct electricity.

(Participants \#20)

\section{Empowered Pedagogical Skills on STEM-based 5E Inquiry} Learning Model

Participants reflected that the professional development program did enhance their understanding of STEM and how STEM could be integrated into the 5E Inquiry Learning Model.

Before class, I did not know what the concept of STEM was. Now, I knew not only the concept of STEM but also the framework of how STEM is embedded into the 5E Inquiry Learning Model where first, students engage through prediction; second, students explore through experiments to test their earlier prediction; third, the teacher and students jointly explain the phenomenon; fourth, students extend by applying the knowledge gained; and finally, students are evaluated on the knowledge acquired.

(Participant \#22)

Before I started this class, I heard about STEM from my sister but I still did not know what STEM was. I thought it was a kind of software. But after the session, I now knew what STEM is, and it is not a kind of software! The experience that I gained in that it [STEM] can be inculcated through the use of the $5 \mathrm{E}$ inquiry teaching method ... truly impresses me. Before that, I thought teachers should always explain and guide the students. But today, from the class session, I learned that teachers should engage students and allow them to explore and observe so that they could find the explanation and solution to the problem, using the $5 \mathrm{E}$ method.

\section{(Participant \#31)}

Through today's experiments, especially the interactive experiments in the class together with my classmates, I learned about the $5 \mathrm{E}$ teaching model from my participation in the engagement activity that arouses my curiosity, exploration of a light bulb and a battery, interpretation of our exploration, extension of our understanding by making a torchlight, and evaluation of our learning. My involvement in the session of light bulbs allows me to understand how to implement STEMbased $5 \mathrm{E}$ in the teaching of primary science.

(Participant \#47)

\section{Heightened Classroom Management Skill on Promoting Collaboration in the Classroom}

It means that the classroom management skill on promoting collaboration in the classroom was enhanced, improved, or sharpened.
Therefore, "Heightened" could either be maintained or be replaced with "Sharpened"/"Improved".

The participants also indicated in their reflections that they have learned about the use of collaboration in the classroom. They acknowledged that collaborative work not only produces many creative ideas but it also establishes more friendship and instills greater motivation to learn and to study harder. Given the benefits of collaborative work in the classroom, the participants opined that they would want to implement this classroom management skill in their respective classes. In short, taken these reflections together, it echoes a heightened classroom management skill on promoting collaboration as reflected in the following quotations of participants' reflections:

I learned that team members must communicate with each other, work together, and accomplish tasks together. This type of collaboration, I can apply in my class.

(Participant \#47)

In this lesson, I learned that knowledge could be acquired through working collaboratively in doing the experiments. The sharing of experiences has also allowed me to make more friends, be motivated to continue to study hard.

(Participant \#49)

Working in groups during the flashlight production in the afternoon helps to produce many creative ideas, especially in the circuit structure.

(Participant \#58)

\section{DISCUSSION}

Despite the limitations in sampling and intervention duration, the professional development program on STEM-based 5E Inquiry Learning Model has positively and significantly impacted on the pedagogical skills of the participants consisting of 78 pre- and in-service science teachers selected from the provinces across China. While the effectiveness of the $5 \mathrm{E}$ Inquiry Learning Model has been widely reported, previous studies on STEM-based 5E Inquiry Learning Model whereby STEM Education is embedded into the 5E Inquiry Learning Model are nowhere to be found. Hence, this explains the novelty and distinctiveness of this research project in terms of integrating STEM Education into the 5E Inquiry Learning Model.

The findings of this study were derived from a group of 78 pre- and in-service Chinese science teachers and there was no comparison group involved, hence its limited generalizability. It means that future studies could actually replicate this study except that they should employ a comparison group in their research methodology and that the sample used should be wider and more representative which include pre- and inservice teachers.

Among the themes that emerged from the participants' reflection is the empowered pedagogical skills in using the 
STEM-based 5E Inquiry Learning Model. Such pedagogical empowerment was captured by means of participants' selfperceived reflections, which may not be enacted in their science classrooms as aspired and perceived. This is because self-perceived empowerment does not in itself empowers practically. Therefore, in a future session of the professional development program, it would be beneficial to ask the participants to generate lesson ideas using learning standards from their respective science curricula. A better assessment of the participants' ability to implement and enact a STEM-based $5 \mathrm{E}$ Inquiry Learning Model could be plausibly gauged on the basis of the lesson ideas generated.

Finally, this STEM-based 5E Inquiry Learning Model which was thoughtfully integrated and used in this research project should be extensively capitalized, widely disseminated, and locally adapted. In the case of teacher education, the ways in which this conceptualized model could be judiciously infused into the teaching curriculum should be given due consideration as part of the reforming science teaching that promotes STEM Education and Inquiry Learning.

NB: The discussion section should be linked and related to the reviewed literature, whether to compare, contrast, critique, or connect to your study. In this current state, it is more of a presentation of data.

\section{CONCLUSION}

The purpose of this research was to determine the effectiveness of the professional development training program on the use of a STEM-based 5E Inquiry Learning Model conducted on a group of participants consisting of 78 pre- and in-service science teachers in China. The quantitative result indicates that there was a markedly increase in the content knowledge of the participants. The triangulation by the qualitative data gives further credence to the quantitative finding in that the pre- and in-service teachers reckoned that their knowledge of the science content used in training was enhanced. In addition, the pre- and in-service teachers also self-perceived that their pedagogical skills on the STEM-based Inquiry Learning were enhanced, and that their classroom management skill on promoting collaboration was equally heightened. While we have yet to actually observe them in action using the STEMbased 5E Inquiry Learning Model, the pre- and in-service teachers noted in their reflection that they would look forward to implementing the STEM-based pedagogical and classroom management skills in their respective educational settings.

\section{ACKNOWLEDGMENT}

We would like to express our sincerest appreciation to the Ministry of Education, Malaysia, for the Research Grant [Coded as 2019-0029-107-02 (FRGS/1/2018/SSI09/UPSI/01/3)] which has enabled this research to be successfully conducted. Equally, we would like to thank the Research Institute of Science Education, Guangxi Normal University, China, for the opportunity to conduct the professional development program, and all the pre- and in-service Chinese science teachers who had actively participated in the training program.

\section{REFERENCES}

Bogdan, R.C., \& Biklen, S.K. (2003). Qualitative Research in Education: An Introduction to Theory and Methods. London, United Kingdom: Pearson Education Group, Inc.

Braun, V., \& Clarke, V. (2006). Using thematic analysis in psychology. Qualitative Research in Psychology, 3(2), 77-101.

Bybee, R., \& Landes, N.M. (1990). Science for life and living: An elementary school science program from biological sciences improvement study (BSCS). The American Biology Teacher, 52(2), 92-98.

Bybee, R.W., Taylor, J.A., Gardner, A., Scotter, P.V., Powell, J.C., Westbrook, A., \& Landes, N. (2006). The BSCS 5E Instructional Model: Origins, Effectiveness, and Applications. Available from: https://www.researchgate.net/publication/242363914_The_BSCS_5E Instructional_Model_Origins_Effectiveness_and_Applications/ link/55e9c9c708ae65b $\overline{6} 389 \mathrm{~b} 59 \mathrm{fa} /$ download. [Last retrieved on 2019 Nov 28].

Cohen, J. (1988). Statistical Power Analysis for the Behavioural Science. $2^{\text {nd }}$ ed. New York: Erlbaum.

Creswell, J.W. (2008). Educational Research: Planning, Conducting, and Evaluating Quantitative and Qualitative Research. $3^{\text {rd }}$ ed. London, United Kingdom: Pearson Education, Inc.

Dai, D.Y., Gerbino, K., \& Daley, M. (2001). Inquiry-based learning in China: Do teachers practice what they preach, and why? Frontiers of Education China, 6(1), 139-157.

Denzin, N.K., \& Lincoln, Y.S. (2000). Handbook of Qualitative Research. $2^{\text {nd }}$ ed. New York, United States: Sage Publications, Inc.

Eggen, P., \& Kauchak, D. (2012). Strategies and Models for Teachers: Teaching Content and Thinking Skills. $6^{\text {th }}$ ed. London, United Kingdom: Pearson.

Gay, L.R., \& Airasian, P. (2000). Educational Research. $6^{\text {th }}$ ed. United States: Prentice Hall.

Gunstone, R., Mulhall, P., \& McKittrick, B. (2009). Physics teachers' perceptions of the difficulty of teaching electricity. Research in Science Education, 39(4), 515-538.

Hu, W., \& Shou, X. (2018). Primary science education in China. In: Lee, Y.J., \& Tan, J. (Eds.), Primary Science Education in East Asia: Contemporary Trends and Issues in Science Education. Berlin, Germany: Springer. pp. 79-105.

Ministry of Education. (2001). Basic Education Curriculum Reform. China: Ministry of Education.

Ministry of Education. (2017). Compulsory Education Primary Science Curriculum Standards. China: Ministry of Education.

Moodeley, L., \& Gaigher, E. (2017). Teaching electric circuits: Teachers' perceptions and learners' misconceptions. Research in Science Education, 49(1), 73-89.

Soeharto, S., Csapo, B., Sarimanah, E., Dewi, F.I., \& Sabri, T. (2019). A review of students' misconceptions in science and their diagnostic assessment tools. Indonesian Journal of Science Education, 8(2), 247-266.

Suchman, J.R. (1966). Developing Inquiry. New York: Science Research Associates, Inc.

Wang, L., Zhu, Y., Jiang, Y., Wei, R., Zhou Y., Guo, Y., Wei, X., Yang, W., \& Liu, E. (2016). Science education research in mainland China. In: Chiu, M.H. (Ed.), Science Education Research and Practice in Asia. New York: Springer. pp. 17-39.

Xinhua. (2017). China Increases Science Education to Boost Innovation. China Daily. Available from: https:/www.chinadaily.com.cn/ china/2017-09/01/content_31421670.htm. [Last retrieved on 2019 Nov 28].

Zeng, N., Zhang, B.H., \& Wang, Q. (2019). STEM fever: Science educators' opportunities and challenges. AIP Conference Proceedings, 2081(020003), 1-12.

Zhang, Y.F. (2018). Experts Call for Emphasis on STEM education in China. China Daily. Available from: https:/www.chinadaily.com. $\mathrm{cn} / \mathrm{a} / 201809 / 20 / \mathrm{WS} 5 \mathrm{ba} 2 \mathrm{e} 43 \mathrm{da} 310 \mathrm{c} 4 \mathrm{cc} 775 \mathrm{e} 72 \mathrm{~d} 1 . \mathrm{html}$. [Last retrieved on 2019 Nov 28]. 